\title{
Le déficit en stéroïde 21 hydroxylase : mécanismes moléculaires
}

Le déficit en stéroïde 21 hydroxylase $(2 \mathrm{I} \mathrm{OH})$ est en cause dans $90 \%$ des hypertrophies surrénales. Le blocage de la synthèse du cortisol qui en résulte conduit à une insuffisance en aldostérone, et à une augmentation de la biosynthèse des androgènes surrénaux, expliquant les deux phénomènes essentiels que sont la perte de sel, et la virilisation des organes génitaux externes chez la fille. Le déficit est transmis comme un caractère autosomique récessif. Sa fréquence dans la forme classique est de I p Io 000 à I p 15000 dans la plupart des ethnies blanches. Elle est plus élevée à la Réunion ( I p 2000 ) et surtout chez des Esquimaux de l'Alaska (I p 700 environ). Il existe une forme atténuée dont la fréquence atteindrait $0,3 \%$ des populations blanches.

L'enzyme qui porte la fonction 2 $\mathrm{IOH}$ siège dans les microsomes; elle fait partie du groupe des cytochromes $\mathrm{P}_{450}$ (voir $\mathrm{m} / \mathrm{s} n^{\circ} 7$, vol 2). La localisation du gène de la 2 I OH sur le chromosome 6, à l'intérieur même du système d'histocompatibilité et au voisinage immédiat de HLA B, est une découverte importante faite par Dupont et coll. en I977 [I]. Certains types HLA sont associés au déficit plus fréquemment que d'autres. Cette liaison étroite permet un diagnostic prénatal dans les familles à risque, en comparant la formule HLA du foetus à celles des parents et de l'enfant atteint. Les méthodes immunologiques, les premières employées, tendent à être supplantées par des sondes d'ADN spécifiques [6].

Une liaison étroite a également été découverte avec plusieurs constituants du complément, $\mathrm{C}_{2}, \mathrm{Bf}$, et surtout $\mathrm{C}_{4}$. L'existence de deux gènes a été démontrée aussi bien pour $\mathrm{C}_{4}$ que pour $2 \mathrm{I} \mathrm{OH}$, résultant sans doute d'une duplication géni- que. L'ordre des gènes dans la zone HLA est montré sur la figure I [2]. L'existence de deux gènes posait le problème de leur rôle : sont-ils tous deux fonctionnels, et si oui, quelle est leur importance relative? Les déficits en 2 I $\mathrm{OH}$ sont de gravité variable, et l'on peut en distinguer quatre degrés : syndrome néonatal de perte de sel avec virilisation, virilisation seule, forme atténuée plus tardive, forme cryptique purement biochimique. Cette variabilité clinique donnait lieu à deux interprétations : si les deux gènes sont fonctionnels, les formes sévères seraient dues à l'inactivité des deux gènes, par exemple par délétion; les formes atténuées résulteraient de l'inactivité d'un seul gène, plus graves si le gène principal est en cause. $\mathrm{Si}$ un seul gène est fonctionnel toutes les anomalies seraient à lui rapporter, et la variabilité tiendrait à la possibilité de lésions différentes au niveau de ce gène.

Des travaux utilisant des sondes d'ADN capables de distinguer les gènes $A$ et $B$ faisaient pencher vers l'hypothèse d'un seul gène fonctionnel : une délétion du gène 2I OH B est fréquente dans des formes sévères associées notamment à l'haplotype HLA BW 47 , alors que des délétions portant sur le locus 2 I OH A ne provoquent aucun trouble $[2,3]$. La question a été définitivement tranchée par deux travaux récents, l'un japonais [4], l'autre américain [5], dont les conclusions sont concordantes. Ils ont analysé la séquence des deux gènes, dont chacun contient 3,4 kilobases et se décompose en dix exons. Seul le gène $B$ est fonctionnel; le gène $A$, lui, est hautement homologue, mais il a subi trois modifications, dont une courte délétion, qui ont provoqué l'apparition de codons de terminaison. Le gène A est donc un " pseudogène", auquel ne correspond aucune protéine.

L'existence de deux gènes voisins très semblables peut donner naissance à des recombinaisons entre eux, pouvant rendre compte d'un certain nombre de déficits en 2I hydroxylase.

J.-C. D.

I. Dupont B, Oberficld S E, Smithurick E M, Lec T D, Levine L S. Close genetic linkage betwcen HLA and congenital adrenal hyperplasia (21-hydroxylasc deficiency). Lancet 1977; ii : 1309-1I.

2. White P C, Grossberger D, Onufer B J, et al. Two genes cncoding stcroid 2I hydroxylasc arc located near the genes encoding the fourth component of complement in man. Proc Natl Acad Sci USA 1985; 82: 1089-93.

3. White P C, New M I, Dupont B. Adrenal 2I-hydroxylasc cytochrome $\mathrm{P}_{45}$ o genes within the MHC class III region. Immunol rev 1985; $87: 123-50$.

4. Higashi Y, Yoshioka H, Yamane M, Gotoh O, Fujii-Kuriyama Y. Complete nucleotide sequence of two steroid 2I hydroxylase genes tandemly arranged in human chromosome: A pscudogenc and a genuine gene. Proc Natl Acad Sci USA 1986; 83:2841-5.

5. White P C, New M I, Dupont B. Structure of human steroid 21-hydroxylase genes. Proc Natl Acad Sci USA 1986; 83 : 5 111-5.

6. Mornet E, Boué J, Raux-Demay M, et al. First trimester prenatal diagnosis of 21 hydroxylase deficiency by linkage analysis to HLA-DNA probes and by 17 -hydroxyprogesterone determination. Human Genet 1986; 73: 358-64.

Centromère...DR- $\mathrm{C}_{2}-\mathrm{Bf}-\mathrm{C}_{4} \mathrm{~A}-21 \mathrm{OHA}-\mathrm{C}_{4} \mathrm{~B}-21 \mathrm{OHB}-\mathbf{B}-\mathbf{C}-\mathbf{A}$

Figure 1. Ordre des gènes sur le chromosome 6. En rouge: Stéroïde 21 hydroxylase. En caractères gras: gènes du système HLA. En caractères maigres : gènes des constituants du complément. 